\title{
Detection of colour vision abnormalities in uncomplicated type 1 diabetic patients with angiographically normal retinas
}

\author{
K J Hardy, J Lipton, M O Scase, D H Foster, J H B Scarpello
}

\begin{abstract}
Colour vision function was assessed in 38 noncomplicated type 1 diabetic patients in whom fluorescein angiography was normal, and was compared with that in 36 age-matched, nondiabetic controls. All of the patients were healthy and none were taking medication except insulin. The eye examination, which was normal in every patient, included the Ishihara and City University tests, measurement of Snellen acuity, slit-lamp examination, tonometry, and fundal photography as well as fluorescein angiography. Colour discrimination ability was measured with the FarnsworthMunsell 100-hue test. Mean (SE) 100-hue test error score for the diabetic group was $86 \cdot 8(8 \cdot 1)$ compared with 28.2 (3.3) for controls, $\mathrm{p}<<0.001$. There was no relation between colour vision abnormalities and diabetes duration $(r=0, p>0.05)$, blood glucose at the time the colour tests were performed $(r=0.4$, p $>0.05)$, most recent glycated haemoglobin result $(r=0.3, p>0.05)$, or the mean of all previous glycated haemoglobin results $(r=0$, $p>0.05)$. It is concluded that colour discrimination may be abnormal in uncomplicated type 1 diabetic patients before the onset of retinopathy, and that colour discrimination losses in diabetes may not be of vascular aetiology. (Brf Ophthalmol 1992; 76: 461-464)
\end{abstract}

Most reports concerning the aetiology of diabetic retinopathy have been concerned with its vascular aspects or their sequelae. ${ }^{1}$ Little evidence exists for a mechanism independent of vascular changes as a cause of diabetic retinal malfunction. For several years it has been known that colour discrimination is abnormal in diabetic patients with either background retinopathy, ${ }^{2}$ or with proliferative retinopathy and maculopathy. ${ }^{3}$ In both groups of patients there is overt vascular damage (diabetic retinopathy) which may be the cause of the colour discrimination losses.

The aim of the present study was to determine whether colour vision is abnormal in young, and non-complicated type 1 diabetic patients without any evidence of vascular disease, and without retinopathy as defined by fluorescein angiography.

\section{Patients and methods}

PATIENTS

We compared 38 type 1 diabetic patients aged between 16 and 40 years with 36 age-matched, non-diabetic controls. Table 1 summarises the clinical details of diabetic patients. Controls were recruited from staff and students at the local university, and staff at the local hospital. There were 23 males and 13 females. All were aged between 16 and 40 years (mean age $25 \cdot 3$ (SD 4.3) years), and all were healthy. None of the controls were taking any form of medication (including the oral contraceptive pill). All the diabetic patients were healthy, and none were taking any medication (including the oral contraceptive pill) except insulin. No patient had evidence of any complications of diabetes, in particular none were hypertensive, or had nephropathy or microalbuminuria; the urinary microalbumin: creatinine ratio (Laurell-Rockett Electrophoresis, laboratory reference range $<2 \cdot 1$ ) was used as a measure of urinary microalbumin excretion and was normal in all patients. Glycated haemoglobin (Corning method, laboratory reference range $5 \cdot 5-8 \cdot 2$ ) was used to assess blood glucose control. The protocol was approved by the district ethical committee, and all subjects gave written informed consent.

\section{EYE EXAMINATION}

Eye examination comprised measurement of corrected Snellen acuity, tonometry, slit-lamp examination of the lens and anterior chamber, fundal photography, and fluorescein angiography. Control subjects were assessed by measures of corrected Snellen acuity and by direct ophthalmoscopy.

\section{COLOUR VISION TESTS}

We tested colour vision on a separate occasion to avoid temporary changes in visual function which may result from slit-lamp examination ${ }^{4}$ and fluorescein angiography. ${ }^{5}$ We used traditional clinical tests: the Ishihara 38-Plate Test (Kanehara \& Co Ltd, Tokyo, Japan), the City University Test, 2nd Edition (Keeler, Windsor, UK),

Table 1 Clinical details of the 38 diabetic patients in whom colour discrimination was studied

\begin{tabular}{lc}
\hline & Diabetics \\
\hline Number & 38 \\
Sex & 27 male $(11$ female) \\
Age (years) & $26 \cdot 1(1 \cdot 1)^{2}$ \\
Age of diabetes onset (years) & $18 \cdot 3(1 \cdot 3)^{2}$ \\
Diabetes duration (years) & $8 \cdot 1(0 \cdot 8)$ \\
Systolic blood pressure (mm Hg) & $123(2)$ \\
Diastolic blood pressure (mm Hg) & $75(1)$ \\
Insulin dose (units/kg) & $0 \cdot 72(0 \cdot 04)$ \\
Serum cholesterol (mmol/) & $4 \cdot 9(0 \cdot 1)$ \\
Urinary microalbumin to creatinine ratio & $1 \cdot 1(0 \cdot 3)$ \\
Glycated haemoglobin $(\%)$ & $10 \cdot 2(0 \cdot 3)$ \\
\hline
\end{tabular}

'Mean (SE). 
Table 2 Colour vision test results in diabetics without retinopathy and in non-diabetic controls

\begin{tabular}{|c|c|c|c|}
\hline & $\begin{array}{l}\text { Diabetics } \\
(n=38)\end{array}$ & $\begin{array}{l}\text { Controls } \\
(n=36)\end{array}$ & Significance \\
\hline Ishihara test & $38 / 38$ & $38 / 38$ & NS \\
\hline City University test & $10 / 10$ & $10 / 10$ & NS \\
\hline $\begin{array}{l}\text { 100-hue test error score } \\
\text { (untransformed) }\end{array}$ & $86.8(8 \cdot 1)^{\circ}$ & $28 \cdot 2(3 \cdot 3)^{2}$ & $\mathrm{p}<<0.001$ \\
\hline Square-root transformation & $8.98(0.3)$ & $4 \cdot 87(0 \cdot 3)$ & $\mathrm{p} \ll<0.001$ \\
\hline $\begin{array}{l}\text { Age-corrected } 100 \text {-hue test } \\
\text { error score }\end{array}$ & $39 \cdot 9(8 \cdot 6)$ & $-12 \cdot 4(3 \cdot 7)$ & $p<<0.001$ \\
\hline
\end{tabular}

- Mean (SE).

and the Farnsworth-Munsell 100-hue test (Kollmorgen Corporation, Baltimore, MD, USA). Each patient performed the tests with one eye, selected at random by computer, under standardised lighting conditions (North Skylight, illuminance $1680 \mathrm{~lx}$, CIE coordinates $x=0.3198$, $y=0 \cdot 3282$, correlated colour temperature $=6127$ K (Northlight, Thorn EMI Lighting, London, UK)). The Farnsworth-Munsell 100-hue test was administered according to the original instructions. ${ }^{6}$ A polar plot of each subject's score was examined visually and was submitted to Fourier analysis to examine for evidence of polarity.

STATISTICAL ANALYSIS

Statistical analysis was by Student's $t$ test (twotailed) for normally distributed data. The MannWhitney $U$ test was used for data that were not

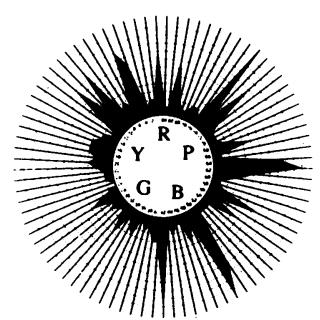

A

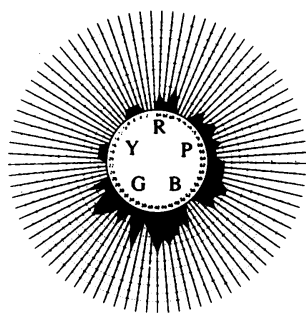

B

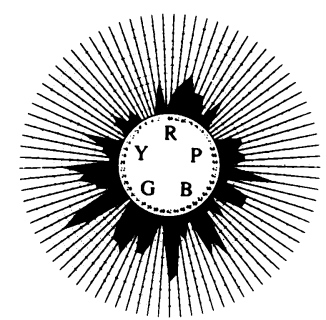

C
Figure 1 Typical polar plots of errors in the 100-hue test for three diabetic patients. Different regions of the colour circle are indicated by letters $(R=$ red, $P=$ purple, $B=$ blue, $Y=y e l l o w$, $G=$ green) with the corresponding cap numbers indicated $(2,4,6$, etc). Note that there is no systematic pattern to the distribution of the errors.
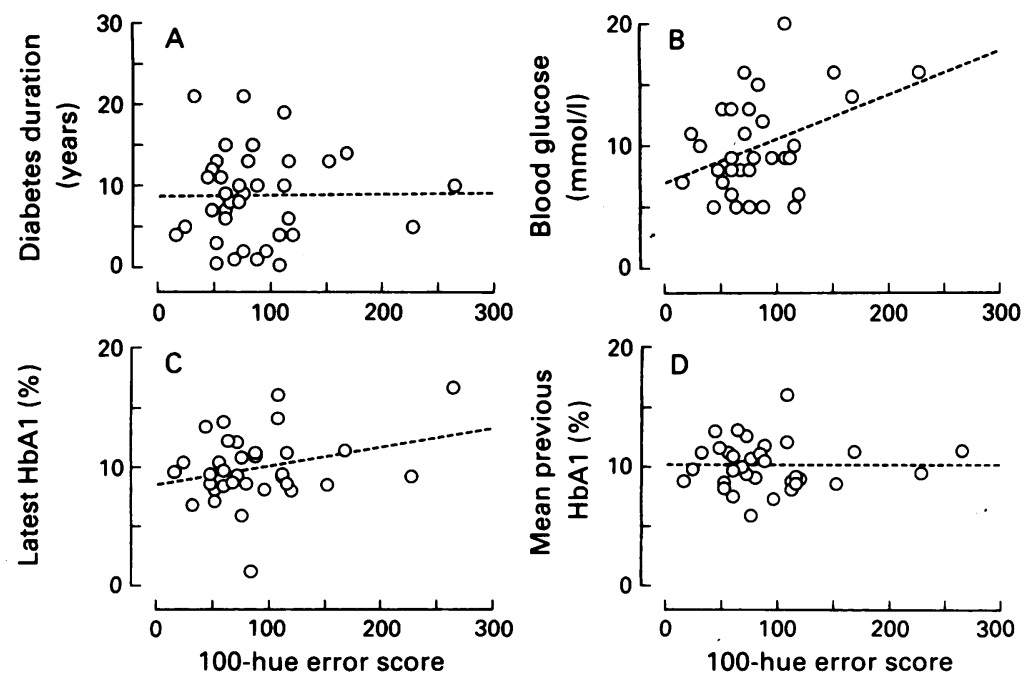

Figure 2 Graphs showing the relationship between colour discrimination ability (100-hue error score) and $(A)$ diabetes duration, $(B)$ blood glucose at the time of colour vision assessment, (C) latest glycated haemoglobin (HBAI) result, and (D) the mean of all previous HBAI results, for 38 diabetic patients without retinopathy. normally distributed. Raw error scores for the 100-hue test are usually positively skewed ${ }^{7}$ and a square-root transformation is often performed to normalise the data. As the appropriateness of this square-root transformation has recently been questioned ${ }^{8}$ both raw error scores and transformed data are presented here.

\section{Results}

By virtue of the conditions of entry into the study, all the diabetic patients had normal Snellen acuity (better than 6/9), an intraocular pressure of less than $21 \mathrm{~mm} \mathrm{Hg}$, and normal ocular media. Fluorescein angiography was also normal in all patients (a single microaneurysm being considered abnormal). Control subjects had normal Snellen acuity (better than 6/9) and no abnormalities of the ocular media or of the retina on direct ophthalmoscopy.

All subjects scored normally on the Ishihara 38-plate test and the City University Test. Results for the 100-hue test in the form of total error scores and their transformations are shown in Table 2. In addition, an age-adjusted mean error score based on Verriest's original norms ${ }^{9}$ is included. This adjusted score must be regarded as an approximation only since our illumination was higher than that used by Verriest. Most $(57 \%)$ of the diabetic group had 100 -hue error scores more than $2 \mathrm{SD}$ values above the mean for the control group.

A polar plot of the 100-hue error score was obtained for each subject, and typical plots for three diabetic patients are shown in Figure 1. No individual patient had evidence of polarity on his or her 100-hue plot, nor did Fourier analysis of individual data reveal any significant polarity $\left(2\right.$-cycle/ 0 -cycle $<0.2$ in all cases; see Allen $^{10}$ ).

By virtue of the conditions of entry in the study, the age-range of the patients and their agematched controls was limited [mean (SD) 26 (7) years]. There was no correlation between age and diabetes duration $(r=0.09, \mathrm{p}>0.05)$, nor between age and 100-hue error score $(r=0 \cdot 12$, $\mathrm{p}>0.05)$. As shown in Figure 2, there were no significant correlations between 100 -hue error score and diabetes duration, blood glucose at the time of colour vision testing, most recent glycated haemoglobin, or the mean of all previous glycated haemoglobin results.

\section{Discussion}

Marked abnormalities of colour vision were detected in young, uncomplicated type 1 diabetic patients in whom fundal photography and fluorescein angiography were normal. The relatively low error scores in the control group compared with the normative data of Verriest ${ }^{9}$ may be due in part to the rigorous exclusion criteria employed in this study. No control (or patient) had evidence of lens abnormalities, which may occur earlier in diabetic patients ${ }^{11}$ and may influence colour discrimination. ${ }^{12}$ The age range was limited to subjects between 16 and 40 years, for although age has an influence on colour discrimination' it varies little over this range. Many drugs, ${ }^{13}$ including the oral contraceptive pill,,$^{14}$ and oral hypoglycaemic agents, ${ }^{13}$ may 
adversely affect colour vision, so that subjects taking medication other than insulin were excluded. Our use of a relatively high level of illumination may also have contributed to the relatively low error scores for the controls. Colour discrimination with the 100 -hue test is known to vary with level of illumination ${ }^{15}$ : low levels produce higher error scores, and may introduce an artefactual tritan-like colour discrimination loss ${ }^{16}$; a higher level was used here to avoid these effects, and also because it was more appropriate for the other colour vision tests we employed. Verriest acknowledged that he had used a lower level of illumination than was usual in his 1963 study, ${ }^{17}$ and that the illuminant in his 1982 study was to compromise between his 1963 illuminant and levels of illumination used by others. Indeed, in a study using the City University colour vision test (also employed in this study), he recommended an illumination level close to that used here. ${ }^{18}$ There were slightly more males in the diabetic group than in the control group, but colour discrimination does not differ significantly between men and women. ${ }^{17}$ Thus, the present findings cannot be attributed to unusually good performance in the control group. Even when performance in the 100-hue test was compared with Verriest's original 1963 data for normal controls, the error scores in the patient group were significantly worse.

Previous studies have shown that diabetic patients with retinopathy, and thus with overt vascular disease, may have abnormal colour discrimination. ${ }^{23}$ In this study, none of the young type 1 diabetic patients had any evidence of either macrovascular or microvascular disease, yet colour discrimination was markedly abnormal in $57 \%$ of patients. It is possible that despite a lack of any evidence of vascular disease a few patients may have had occult vasculopathy. It is unlikely, however, in view of the low age of the group and their short duration of diabetes that occult vascular disease could have accounted for the impaired colour discrimination present in so many patients. It is known that with increasing diabetes duration the microvascular complications of diabetes become more frequent. ${ }^{19-21}$ No association between colour discrimination loss and duration of diabetes was present in this study, nor have previous studies found such an association. ${ }^{222}$ The incidence of microvascular complications is increased in those patients with the highest glycated haemoglobin values, ${ }^{23}$ particularly when an aggregate of previous glycated haemoglobin results is used. ${ }^{24}$ Like earlier studies of colour vision in diabetes, ${ }^{25}$ there was no relationship, in this study, between either the latest glycated haemoglobin result, or the mean of all the previous glycated haemoglobin results, and colour discrimination ability. The evidence from this study thus supports the view that colour discrimination losses in diabetic patients without retinopathy may be of a non-vascular aetiology. By what mechanism could these colour vision changes be mediated? Several possibilities exist. (1) There may be osmotic distortion of the retina. Impairment of colour discrimination ability might result from fluid shifts in the retina causing distortion and thus dysfunction of the neural cells, in the same way that acute changes in blood glucose lead to refractive errors secondary to osmotic distortion of the lens. ${ }^{26}$ This hypothesis would be supported by changes in colour discrimination ability occurring at the time of acute changes in blood glucose. This change of colour vision with blood glucose level has so far been convincingly demonstrated only during hypoglycaemia, ${ }^{27}$ when the effects may have resulted directly from neuroglycopenia. (2) There may be disordered metabolism of neural cells. Although the cause of neuronal dysfunction in diabetic neuropathy is unclear, diabetes may damage the nerve directly, or indirectly through changes in the microcirculation. Interest has recently focused on the sorbitol pathway, and on aldose-reductase inhibitors which inhibit the conversion of glucose to sorbitol. The use of aldose-reductase inhibitors in the management of diabetic neuropathy in humans has so far been only modestly encouraging, ${ }^{28} 29$ and in a randomised, placebo-controlled study of 41 diabetics, treatment with ponalrestat for 1 year did not improve visual dysfunction. ${ }^{30}$ Another recent therapy in the treatment of diabetic neuropathy has been dietary supplementation with the essential fatty acid derivative, $\gamma$ linoleic acid (GLA). This and other essential fatty acid derivatives are important constituents of the phospholipids of neuronal membranes (and of the cone-receptors); and it is known that their formation is impaired in diabetes. Studies in animals have shown that diabetic neuropathy can be prevented and in some cases reversed by the administration of GLA, ${ }^{3132}$ and in humans GLA is significantly better than placebo in the treatment of diabetic neuropathy. ${ }^{33}$ It is possible that abnormalities of essential fatty acid metabolism are also involved in the development of diabetic retinopathy, and it is interesting to note that almost 30 years ago King et $a l^{3+}$ demonstrated a significant reduction in exudative retinopathy in patients treated with fatty acid supplements.

In summary, this study has demonstrated marked abnormalities of colour vision in diabetic patients in whom there was no evidence of retinopathy or vascular disease. This suggests that the aetiology of early colour vision loss is not vascular. Whether retinal dysfunction is directly attributable to changes in blood glucose, or whether it results from derangement of other metabolic pathways is as yet unknown.

We thank Professor J D Moreland, Dr S R Pratt, and Mr R Brown for their help and advice, the Nursing Staff from the Diabetes Clinic at North Staffs Royal Infirmary for their assistance in recruiting the patients, and Mrs E Ward for her secretaria assistance. This work was supported by a grant from Scotia Pharmaceuticals Limited, Woodbridge Meadows, Guildford, Surrey.

1 Smith R. Diabetes and retinal function. Br F Ophthalmol 1990 74: 385 .

2 Roy MS, Gunkel RD, Podgor MJ. Color vision in early diabetic retinopathy. Arch Ophthalmol 1986; 104: 225-8.

3 Bresnick GH, Condit RS, Palta M, Korth K, Groo A, Syrjal $S$. Association of hue discrimination loss and diabetic retinopathy. Arch Ophthalmol 1985; 103: 1317-24.

4 Ghafour IM, Foulds WS, Allan D. Short-term effect of slitlamp illumination and argon laser light on visual function of diabetic and non-diabetic subjects. Br $\mathcal{F}$ Ophthalmol 1984 68: 298-302.

5 Fontana M, Verriest G. Modification by fluoangiography of colour vision in diabetic patients. Bull Soc Belge Ophtal 1985; 215: 37-48. 
6 Farnsworth D. The Farnsworth-Munsell 100-Hue Test Manual. Baltimore: Munsell Color Company, 1957.

7 Kinnear PR. Proposals for scoring and assessing the 100-hue test. Vision Res 1970; 10: 423-33.

8 Lakowski R. Uses and abuses of the Farnsworth-Munsell 100 Hue Test. In: B Drum, G Verriest, eds. Colour vision deficiencies IX. Dordecht: Kluwer, 1989: 375-95.

9 Verriest G. Further studies on acquired deficiency of color discrimination. F Opt Soc Am 1963; 53: 185-95.

10 Allan D. Fourier analysis and the Farnsworth-Munsell 100 hue test. Ophthal Physiol Opt 1985; 5: 337-42.

11 Lutze M, Bresnick GH. Lenses of diabetic patients 'yellow' at an accelerated rate similar to older normals. Invest Ophthalmol Vis Sci 1991; 32: 194-9.

12 Ruddock KH. The effect of age upon colour vision II changes with age in light transmission of the ocular media. Vision Res $1965 ; 5: 47-58$.

13 Lyle WM. Drugs and conditions which may affect color vision. Part I - Drugs and chemicals. F Am Opt Soc Assoc 1974; 45: 47-60.

14 Lakowski R, Morton A. The effect of oral contraceptives on colour vision in diabetic women. Can 7 Ophthal 1977; 12: 89-97.

15 Dain SJ, Pereira SM, Palmer B, Lewis P, Hammond T. Illuminance and the FM 100 hue test. In: Colour vision deficiencies $V$. Bristol: Adam Hilger, 1980: 162-3.

16 Vola JL, Leprince G, Cornu L, Saracco JB. The 100 Hue at mesopic level. Mod Probl Ophthal 1978; 19: 67-70.

17 Verriest G, Van Laethem J, Uvijls A. A new assessment of the normal ranges of the Farnsworth-Munsell 100-Hue Test scores. Am $\mathcal{F}$ Ophthalmol 1982; 93: 635-42.

18 Verriest G, Caluwaerts MR. An evaluation of three new colour vision tests. Mod Probl Ophthal 1978; 19: 131-5.

19 Klein R, Klein BEK, Moss SE, Davis MD, DeMets DL. Retinopathy in young-onset diabetic patients. Diabetes Care 1985; 8: 311-5

20 Andersen AR, Christiansen JS, Andersen JK, Kreiner S, Deckert T. Diabetic nephropathy in type 1 (insulindependent) diabetes: an epidemiological study. Diabetologia dependent) diabetes:

21 Anonymous. Diabetic skin, joints, and eyes - how are they related? Lancet 1987; ii: 313-4.

22 Greenstein V, Sarter B, Hood D, Noble K, Carr R. Hue discrimination and $\mathrm{s}$ cone pathway sensitivity in early diabetic retinopathy. Invest Ophthalmol Vis Sci 1990; 31: 1008-14.

23 Klein R, Klein BEK, Moss SE, Davis MD, DeMets DL. Glycosylated hemoglobin predicts the incidence and progression of diabetic retinopathy. $\mathcal{F A M A} 1988 ; 260: 2864-71$.

24 McCance DR, Hadden DR, Atkinson AB, Archer DB, Kennedy L. Long-term glycaemic control and diabetic retinopathy. L ancet 1989; ii: 824-8.

25 Sawicki PT, Karschny L, Stolpe V, Wolf E, Berger M. Color discrimination and accuracy of blood glucose self-monitoring in Type 1 diabetic patients. Diabetes Care 1991;14: ing in $135-7$.

26 Duke-Elder WS. Changes in refraction in diabetes mellitus. BrF Ophthalmol 1925; 9: 167-87.

27 Harrad RA, Cockram CS, Plumb AP, Stone S, Fenwick P Sonksen $P H$. The effect of hypoglycaemia on visual function a clinical and electrophysiological study. Clin Sci 1985; 69: 673-9.

28 Boulton AJM, Levin S, Comstock J. A multicentre trial of the aldose-reductase inhibitor, tolrestat, in patients with symptomatic diabetic neuropathy Diabetologia 1990; 33: 431-7.

29 Florkowski CM, Rowe BR, Nightingale S, Harvey TC Barnett AH. Clinical and neurophysiological studies of aldose reductase inhibitor ponalrestat in chronic symptomatic diabetic peripheral neuropathy. Diabetes 1991; 40: matic diab

30 Midena E, Segato T, Radin S, Fedele D, Crepaldi G. Retinal and visual function in diabetics with background retinopathy treated with ponalrestat, an aldose reductase inhibitor. Invest Ophthalmol Vis Sci 1991; 32: 1141.

31 Julu POO. Essential fatty acids prevent slowed nerve conduction in streptozotocin diabetic rats. $\mathcal{F}$ Diabetic Complications 1988; 2: 185-8.

32 Tomlinson DR, Robinson JP, Compton AM, Keen P. Essential fatty acid treatment - effects on nerve conduction, polyol pathway and axonal transport in streptozotocin diabetic rats. pathway and axonal transport
Diabetologia 1989; 32: 655-9.

33 Jamal GA, Carmichael $H$. The effect of gamma-linoleic acid on human diabetic peripheral neuropathy: a double-blind placebo-controlled trial. Diabetic Med 1990; 7: 319-23.

34 King RC, Dobree JH, Kok D'A, Foulds WS, Dangerfield WG. Exudative diabetic retinopathy. Spontaneous changes and effects of a corn oil diet. Br $\mathcal{Y}$ Ophthalmol 1963; 47:66672. 